\title{
An Empirical Study on Emerging Trends in Artificial Intelligence and its Impact on Higher Education
}

\author{
Virendra Gawande, PhD \\ College of Applied Sciences-Ibri, \\ Ministry of Higher Education, \\ Oman
}

\author{
Huda Al Badi \\ College of Applied Sciences-lbri, \\ Ministry of Higher Education, \\ Oman
}

\author{
Khaloud Al Makharoumi \\ College of Applied Sciences-lbri, \\ Ministry of Higher Education,
}

\begin{abstract}
This paper investigates the various emerging trends in Artificial Intelligence (AI), and their impact on teaching and learning practices in Higher Education Institutions (HEIs). Many of the these AI technologies like Hologram technology, the technologies that supports Ubiquitous learning, technologies for Automated evaluations and grading, Green Computing, and Blended learning methodologies, can be used efficiently to shape the future of higher education and can bring innovations in teaching and learning. This study investigates the opportunities and the challenges in each of these areas, which might serve as a guideline for its adoption, and can also be extended further in the direction of research.
\end{abstract}

\section{Keywords}

Artificial Intelligence, Hologram technology, Ubiquitous learning, Automated evaluation, Green computing, Blended learning

\section{INTRODUCTION}

The term Artificial Intelligence (AI) refers to the use of technology aided systems that may have human like capacities for problem solving, and also have thinking abilities. Recent developments in the area of AI, is undoubtedly been substantial, and clearly visible on various aspects in our society, ranging from rendering medical services, aircraft flight control management, manufacturing, satellite control, to leaving its marks in the area of education as well. No doubt, the emergence of AI in these areas is bringing a positive impact all over. Innovations in the area of AI in education, is advocating new possibilities that have an enormous potential to bring a fundamental reform in higher education governance, and bring a positive change. This study explores some of the potential technologies in the area of AI that can be utilized to leverage the Higher Education further.

\section{PROBLEM STATEMENT}

Rising number of students all over the Higher Education Institutions (HEIs) every year, with the limited available resources or inability to provide the resources adequately due to various financial or economic constraints at HEIs, demands a need for innovative solutions in the area of Higher Education teaching and learning. Some of the earlier researches have clearly indicated that the emerging developments in AI has a tremendous potential to deal with this issue. It's not only dealing with increasing number of students, but there are issues like, self-paced learning, differentiated instruction within a classroom, ubiquitous learning, increasing cost of delivering the education in traditional setup, and many more that can be addressed by effectively using the potential of AI in higher education.

\section{ANALYSIS}

\subsection{Hologram Technology}

Holography is a form of photography that records the light dispersed from a body and then generates a realistic image as $3 \mathrm{D}$ Hologram. The 3D hologram technology can be integrated in classrooms that may add a new dimension to the process of teaching and learning. The implication of this technology is vast and may enable the learners to experience the realistic content via 3D Hologram visualizations, and thereby helping to improve their learning curves. Holography is the technique of making holograms. Developments in Hologram technology made it possible to produce entirely computer-generated holograms to simulate the objects or details that never existed.

\subsubsection{D Hologram Technology in education}

In higher education 3D Hologram Technology may be used in many different forms. For instance, a remotely located teacher can virtually be visible in the classroom in 3D form, and can interact with the students like a real life character. "This technology was showcased by Edex, at the BETT2000 educational technology show in London" [5] [12]. This technology can further enhance the process by virtually visualizing prominent historical characters from the past, and interact with audience. The Seoul's Alive Gallery Project, uses 3D hologram technology and brings various world-renowned masterpieces of Western art to life again. It also includes the virtual Mona Lisa answering questions from students. Also another famous character Michelangelo explaining about fresco technique that he used in his famous painting "The Last Judgment", and also explained the work of another masterpiece that he had completed earlier on the ceiling of the Sistine Chapel, "The Creation of Adam" [8]. However, 3D Hologram Technology, also have some disadvantages. It needs to have a very fast and expensive next-generation broadband. "To use this technology efficiently, it requires a well-equipped studio with the attuned lighting and seamless video streaming systems that might costs around 150,000 USD, as well as a state-of-the-art display screens to visualize the holograms that costs around 215,000 USD" [7].

In education, the hologram may contribute an important role. The reason is that students can be able to actually view and visualize the concepts that are being taught during the class. This might help them further to understand the topics in an 
efficient manner and enhance the students learning process. When the concepts are visualized in front of students, they can understand it in a much easier manner. Instructors just need to strike the right balance of coaching to make things happen for their students.

\subsection{Ubiquitous learning}

Jones and Jun [20], defines "Ubiquitous learning environment as a setting in which students can become totally immersed in the learning process".

Ubiquitous = pervasive, omnipresent, everywhere

Learning = educational, instructive, didactic, pedagogical

Environment $=$ surroundings, setting, situation, atmosphere

Thus, ubiquitous learning environment (ULE) is a setting that includes pervasive education or learning tools. "Educational resources are available and in progressing all around the student, but the student may not even be conscious of the learning process. Educational resources are present in the embedded objects and students do not have to do any efforts in order to learn" [20].

The term 'Ubiquitous Computing' was coined by Mark Weiser in the late 1980s. "Weiser's third wave in computing highlights a many-to-one relationship between computer and human" [30]. This becomes more obvious and evident in the present ubiquitous era. This also connects to the idea of u-learning that is currently in its emerging form. Every student is having an interaction with many embedded computing devices. In the ubiquitous classroom, students is having access to Ubiquitous Space (u-space) and interact with the multiple computing devices.

With the evolution of more pervasive forms technologies, the concept of ubiquitous computing and u-learning is getting more embedded in various aspects of our life. Wearable computers and embedded microchips are the examples. Many of the technologies have become integrated into our lives over the years, example includes; play stations, televisions, PCs, the Internet and smart phones. Ubiquitous technology and ulearning may be the new hope for the future of education globally.

\subsection{Green computing}

"Efforts to minimize the power consumption associated with the use of personal computers is referred to as green computing" [29]. This is also leads to the practices of using computing resources in efficient and environment friendly manner. Various HEIs have realized this and started to feature on their websites about green computing practices and the possible ways to reduce carbon footprints. "Some examples are, Cornell University, University of San Francisco, University of Texas at Arlington, University of Colorado at Boulder, and University of Miami School of Medicine" [29]. He also suggests the following possible ways to decrease energy consumption at HEIs:

- Power management: "to manage the power supply to a computer devices so as to minimize the power consumption, without affecting the quantity and quality of the work" [16].

- E-mails: Users may be encouraged to use e-mails, instead of paper memos for any internal/external communications to reduce energy consumption.

- Online learning: Online learning platforms may use learning management systems (LMS) and videoconferencing to cut-back on the need for traditional classrooms and also further reducing the costs associated with travel and energy consumption.

The demand of online learning is increasing rapidly, and this new drift has environmental benefits also. It is now possible for students or learners to get enrolled for the course(s) online from anywhere, without a need to physically travel to the HEI campus, and hence minimizing their carbon footprints on the environment. Travelling results in $\mathrm{CO}_{2}$ emissions and also significant travelling expenses. Cornell University website highlights, "The combination of travel to and from the location of the training, as well as the facilities that house the learners and the printed handouts take their toll on the environment" [9]. Online learning may also eliminate or reduce the need for physical resources like number of classrooms, recurring electrical and maintenance costs associated with Airconditioning and lighting, also the regular course assignments and the handouts can be provided online using LMS, resulting in the reduced cost of printing and the paper usage. Such cost effective measures can minimize HEI's energy footprints on the environment.

\subsection{Blended Learning}

The term "Blended Learning", is getting widely used in academic publications and conferences in addition in its use in industry field. Blended learning can be defined as the process of combining and integrating various web-based technologies such as virtual classroom, active learning and streaming video to achieve different educational objectives.

Many studies have been conducted to identify the advantages and challenges in the design and implementation of blended learning. "Blended learning merges between different learning strategies to meet specific educational objectives, which is the reason why it becomes emerging trend in higher education" [22]. For instance, Allen \& Seaman [2], state that "blended learning is emerging nowadays globally in educational context". "Students learning, interaction and participation has been improved when online sessions were combined with traditional courses" [1] [10] [21]. "Flexibility and enhancement of feedback time has been provided by using blended learning" [1] [13] [21] [27].

"Blended learning may be considered as a better approach as it improves the learning process by making it continues rather than single time event and encourages the students to study by their own outside the classroom" [11]. On the other side, there are many different challenges that can be identified by implementation of blended learning. According to Alebaikan \& Troudi [1], blended learning is increasing the workload for instructors as they will prepare for both online and traditional sessions. There are no clear goals and objectives of using blended learning in education context [28]. Difficulty in finding the correct combining of traditional and online learning for instructors is one of the challenges of blended learning according to Korr, et al. [21]. Many different challenges of blended learning can happen because of lack of institutional definition for blended learning as well as lake of instructors' 
capacity to engage with blended learning which leads to misunderstanding of blended learning practices and principles [25]. Lack of policy, lack of instructors' support, lack of technology, and large number of students in a class, leads to failure in implementation of blended learning.

There are various HEIs implementing blended learning in its curriculum. East China Normal University (ECNU) has embedded blended learning at various levels of courses and observed various impact on learning and teaching. There are many reasons for adapting blended learning at ECNU such as instructors who are very much experienced were utilized at different e-learning platforms, students were from the post-1990 generation so they are very much familiar with electronic products and the internet. University realized that, blended learning is emerging trend and adapting it would positively affect the learning process.

Various important results were found at ECNU on the adaption of blended learning. For instance, students are required to participate in an active way which further improved students' participation and interaction. Also, teachers are encouraged to interact with students online and give them feedback about their performance which enhanced the relationship between students and instructors. Another example of the university which has adapted blended learning is University of Western Australia that consider blended learning as one of key factors of the strategic plan for innovations in education. The UWA integrated blended learning using Blackboard Learn ${ }^{\mathrm{TM}}$ LMS, and this approach lead to many benefits such as engagement, challenging and transforming student learning through course contents, UWA provides students with various learning experiences and collaborative learning environments and help the students and researchers to conduct different research projects in the area of blended learning. University Sains Malaysia (USM) also adapted blended learning as one of the main interactive learning environments. They merge the strategies of blended learning in university online portal eLearn@USM where the teachers can design and implement online sessions which then the students can have access to. One of the main results in adapting blended learning at USM is empower instructors and students by adaption of various learning tools to improve the teaching and learning experiences. Chiang Mai University, Thailand is also supporting the blended learning practices since 2000 until now, it offers 1300 online courses that combined with face-to-face interaction. "Advantages of adapting blended learning at CMU is facilitated students' learning performance and improved the quality of instruction" [23].

\subsection{Automated Evaluations}

Essay evaluations is one of numerous ways to assess the learning process of students at HEIs. In this era of emerging technologies, an essay evaluation is done in a more advanced way using e-learning tools. According to Amalia et al. [3], "The most punctual framework proposed for paper evaluation is the Extend Exposition Grader (EEG) which was centering on the composing fashion of a given exposition in arrange to supply the score. The composing fashion concentrates on paper length and mechanics such as capitalization, spelling mistake, language structure and phrasing. Clearly this approach was criticized due to the need of semantic examination in which the substance is being ignored".

Harshada Satav et al. [15], has displayed an evaluation framework based on SQL and Microsoft.Net. They designed an examination framework for computer application base. In addition, their framework included diverse sorts of questions that related to computer application such as multiple choice, fill in the blanks, true /false, programming questions [4].

Jaballah et al. [19], designed an Arabic evaluation framework for undergraduate students at College of Sharjah. The framework included examination and evaluating subsystems of distinctive sorts of questions such as true/false, multiple choice, fill ups and paper address sorts. The exam paper is created consequently by the examination framework. In any case, their reviewing subsystem was not robotized and the reviewing is done physically by the educator through an evaluation portal. Xiangyun D. et al. [31], proposed an examination framework which gives login action recording, clients administration, test address administration. It incorporates examination subsystem and reviewing subsystem that based on matching answers with the answers key.

Programmed exposition scoring frameworks was carried out by Rudner \& Liang [26], this study was based on the Multivariate Bernoulli Model (MBM) and Bernoulli Model (BM) strategies. This strategy got the precision of $80 \%$. Other assist inquire about was conducted [6], utilizing the K-Nearest Neighbor algorithm. Each paper was changed into the Vector Space Model (VSM). This ponder executes the preprocessing handle such as halt words evacuation, highlight choice of the paper and the esteem of each vector is communicated by term frequencyinverse document frequency (TF-IDF). This consider implemented cosine within the KNN calculation to calculate the likeness of an exposition and reply key. Tests on the CET-4 (College English Text) paper in China Learner English Corpus (CLEC) appeared accuracy above $76 \%$.

Table 1 - Comparison between Human and Computer Essay Assessment from the year 2003 to 2014 [24]

\begin{tabular}{|c|c|c|c|}
\hline S No & Machine Assessment & Reported by & Result \\
\hline 1 & Project Essay Grade (PEG) & Valenti, Neri and Cucchiarelli (2003) & 87 (correlation) \\
\hline 2 & Intelligent Essay Assessor (IEA) & Valenti, Neri and Cucchiarelli (2003) & $85-91$ (agreem*) \\
\hline 3 & Educational Testing service I & Valenti, Neri and Cucchiarelli (2003) & $93-96$ (accuracy) \\
\hline 4 & Electronic Essay Rater (E-Rater) & Valenti, Neri and Cucchiarelli (2003) & $87-94$ (agreem*) \\
\hline 5 & C-Rater & Valenti, Neri and Cucchiarelli (2003) & 80 (accuracy) \\
\hline 6 & BETSY & Valenti, Neri and Cucchiarelli (2003) & 8 \\
\hline
\end{tabular}




\begin{tabular}{|c|c|c|c|}
\hline 7 & $\begin{array}{c}\text { Intelligent Essay Marking } \\
\text { System }\end{array}$ & Valenti, Neri and Cucchiarelli (2003) & 80 (correlation) \\
\hline 8 & Automark & Valenti, Neri and Cucchiarelli (2003) & $93-96$ (correlation) \\
\hline 9 & IntelliMetric $^{\mathrm{TM}}$ & Wang and Brown (2007) & $\begin{array}{c}\text { Non-significant mean score differences } \\
\text { between AES and human scoring }\end{array}$ \\
\hline 10 & Whitesmoke & Toranj and Ansari (2012) & No significant correlation \\
\hline 11 & Criterion & Huang (2014) & Weak correlation \\
\hline
\end{tabular}

In fact, the initial Automated Essay Scoring (AES) was created by an English educator, Ellis Page, in 1966, called his development as Page Essay Grade (PEG). Within the starting, PEG managed with surface content highlights investigation like number of words, normal sentence length until afterward it was able to incorporate other more important highlights like syntactic rightness and word choice. Such highlights are not as it were important to human raters but they provide awesome academic impacts on the field of English dialect educating and learning. It was found that major scoring engines generally comparable to human graders in unwavering quality [24].

The study conducted by Graesser et al. [14], to develop an automated evaluation system enabled teachers to organize questions, model answers and grading conveniently. To measure the accuracy of the system, they deployed three scenarios; Scenario1: $100 \%$ similarity level, Scenario2: Synonym similarity (words with same meaning), and Scenario3: 0\% similarity level. As a result, the accuracy of this system compared to teachers' manual assessment was found to be $83.3 \%$.

\section{CONCLUSION}

The emerging technological developments in AI can have tremendous positive impact on teaching and learning at HEIs. It's not only for the quality of education but also can be useful in economic aspects.

It's a vital need for all the HEIs to consider the solutions offered by AI, to improve their pedagogical models, bring a reform in their infrastructure, and to establish a relationship with AI technologies. AI in education have a vast potential to shape the future of education. Eventually, these AI solutions may offer new opportunities for education for all, while maintaining the integrity and the core values of higher education.

There is a vital need for specific research on the development and ethical implications of AI. Also it is important to continue further research in the direction of changing pedagogical roles i.e., technology-mediated pedagogy with the possible new set of graduate attributes having a sharp focus on efficient learning.

\section{REFERENCES}

[1]. Alebaikan R. \& Troudi S. (2010). Blended learning in Saudi universities: challenges \& perspectives. ALT-J Research in Learning Technology, 18(1), 49-59.

[2]. Allen I. E. \& Seaman J. (2006). Making the grade: Online education in the United States. Needham, MA: The Sloan Consortium.

[3]. Amalia A., Gunawan D., Fithri Y. \& Aulia I. (2019, June).
Automated Bahasa Indonesia essay evaluation with latent semantic analysis. In Journal of Physics: Conference Series (Vol. 1235, No. 1, p. 012100). IOP Publishing.

[4]. Baker R. S., D'Mello S. K., Rodrigo M. M. T. \& Graesser A. C. (2010). Better to be frustrated than bored: The incidence, persistence \& impact of learners' cognitiveaffective states during interactions with three different computer-based learning environments. International Journal of Human-Computer Studies, 68(4), 223-241.

[5]. BBC News. (2000, January 13). Meet the hologram teacher. BBC News. Retrieved November 21, 2009.

[6]. Bin L., Jun L., Jian-Min Y. \& Qiao-Ming Z. (2008). Automated Essay Scoring Using the KNN Algorithm, International Conference on Computer Science \& Software Engineering (IEEE).

[7]. Bobolicu G., "Live hologram communication to become reality within five years", 2009.

[8]. Cho J. (2008, June 13). Talking to Mona Lisa \& Michelangelo. ABC News.

[9]. Cornell University (2008, November 26). "Reducing Your Carbon Footprint with eLearning," eCornell.

[10].DeLacey B. J., \& Leonard D. A. (2002). Case study on technology \& distance in education at the Harvard Business School. Educational Technology \& Society, 5(2), 13-28.

[11].Eddy L. J., Nor-Aziah A., \& Jasmine J. (2014). Blended Learning: Examining Concepts \& Practices. In E. Mohamed-Amin (Ed.), Blended \& Flipped Learning: Case Studies in Malaysian HEIs. Bangi: Pusat Pengajaran \& Teknologi Pembelajaran, Universiti Kebangsaan Malaysia.

[12]. Ghuloum H. (2010). 3D Hologram Technology in Learning Environment, Proceedings of Informing Science \& IT Education Conference.

[13]. Gomez J., \& Igado M. (2008). Blended learning: The key to success in a training company. International Journal of Instructional Technology \& Distance Learning, 5(8).

[14].Graesser A. C., Wiemer-Hastings P., Wiemer-Hastings K., Harter D., Tutoring Research Group, T. R. G., \& Person N. (2000). Using latent semantic analysis to evaluate the contributions of students in AutoTutor. Interactive learning environments, 8(2), 129-147.

[15]. Harshada Satav, Trupti Nanekar, Supriya Pingale \& Nupur (2012). SQL Based Paperless Examination System, International Knowledge Sharing Platform. 
[16].Hasimah A. Rahman, Mohd. Shah Majid, Mohd. Yusri Hassan, \& Tiw S. Lian (2007). "Energy Savings Through Power Management in the Desktop Computer," ELEKTRIKA, vol. 9, no. 2, p. 28.

[17].Hazar M. J., Toman Z. H., \& Toman S. H. (2019, September). Automated Scoring for Essay Questions In Elearning. In Journal of Physics: Conference Series (Vol. 1294, No. 4). IOP Publishing.

[18].Ho Y. S., Sang J., Ro Y. M., Kim J., \& Wu F. (Eds.). (2015). Advances in Multimedia Information ProcessingPCM 2015: 16th Pacific-Rim Conference on Multimedia, Gwangju, South Korea, September 16-18, 2015, Proceedings (Vol. 9314). Springer.

[19].Jaballah M., Harous S., \& Yagi S. M. (2008, April). UOS EASY EXAM Arabic Computer-Based Examination System. In Information \& Communication Technologies: From Theory to Applications, 2008. ICTTA 2008. 3rd International Conference on (pp. 1-5). IEEE.

[20].Jones V. \& Jun H. Jo (2004). Ubiquitous learning environment: An adaptive teaching system using ubiquitous technology, School of Information Technology, Griffith University Gold Coast.

[21].Korr J., Derwin E. B., Greene K., \& Sokoloff W. (2012). Transitioning an Adult-Serving University to a Blended Learning Model. The Journal of Continuing Higher Education, 60, 2-11.

[22].Levin S., Whitsett D., \& Wood G. (2013). Teaching MSW social work practice in a blended online learning environment. Journal of Teaching in Social Work, 408-420.

[23].Lim, Ping \& Wing C., \& Libing. (2017). Blended Learning for quality higher education: selected case studies on Implementation from Asia-Pacific. United Nations Educational, Scientific \& Cultural Organization.

[24].Manap M. R., Ramli N. F., \& Kassim A. A. M. (2019). Web 2.0 automated essay scoring application and human ESL essay assessment: a comparison study. European Journal of English Language Teaching.

[25]. Mirriahi N. \& Alonzo D. (2015) 'Shedding light on students' technology preferences: implications for academic development', Journal of University Teaching \& Learning Practice, vol. 12, no. 1, pp. 1-14.

[26]. Rudner L. M. \& Liang T. (2002). Automated Essay Scoring Using Bayes' Theorem vol. 1.

[27]. Sharpe R., Benfield G., Roberts G., \& Francis R. (2006). The undergraduate experience of blended e-learning: A review of UK literature \& practice. The Higher Education Academy.

[28].Smith K., \& Hill J. (2019). Defining the nature of blended learning through its depiction in current research. Higher Education Research and Development, 38(2), 383-397.

[29]. Thompson J. (October, 2009), "Three Approaches to Green Computing on Campus", Buffalo, New York, United States.

[30].Weiser M. (1991). The computer for the twenty-first century. Scientific American, September, 94-104.

[31].Xiangyun D., Youmen C. A., Maha E. (September 2019). Influence of the Practicum Experience on Student Teachers' Beliefs about their Role in EFL Classrooms, International Journal of Learning, Teaching and Educational Research Vol. 18, No. 8. 